\title{
Association of serum ADAMTS-7 levels with left ventricular reverse remodeling after ST-elevation myocardial infarction
}

\author{
Wenjing Wu, Jiahui Li, Changan Yu, Yanxiang Gao, Shuying Fan, Xiaojun Ye, Yong Wang and Jingang Zheng*
}

\begin{abstract}
Background: Left ventricular reverse remodeling (LVRR) in patients with ST-elevation myocardial infarction (STEMI) is associated with a good prognosis. Serum levels of ADAMTS-7 might be used for the prognosis of STEMI. This study aimed to investigate the relationship between serum ADAMTS-7 levels and LVRR.

Methods: This was a prospective study of 104 patients with STEMI who underwent revascularization and 63 controls. ADAMTS-7 serum levels were measured on days 1, 3, and 7 and in months 1 and 6 after STEMI. A decrease $\geq 15 \%$ of the left ventricular end-systolic volume at 6 months was defined as LVRR.

Results: The serum levels of ADAMTS-7 in patients with LVRR were lower than those without LVRR (3.84 \pm 2.26 vs. $5.02 \pm 2.54, P=0.032$ ) 7 days after STEMI and the difference between day 7 and day 1 ( $\triangle$ ADAMTS-7) was even significantly lower $(-1.31 \pm 0.94$ vs. $-0.30 \pm 0.22, P=0.021)$. Multivariate analysis showed that $\triangle A D A M T S-7$ (day 7 minus day 1 ) was independently associated with LVRR $(\mathrm{OR}=-0.322,95 \% \mathrm{Cl}=-0.996$ to $-0.074, P=0.028)$. Receiver operating characteristic (ROC) curve analysis showed that LVRR could be predicted (sensitivity $89 \%$, specificity $82 \%$, and area under the curve 0.896) when $\triangle$ ADAMTS-7 ${ }_{\text {(day } 7 \text { minus day 1) }}$ was $<-0.39$.

Conclusions: $\triangle$ ADAMTS-7 $_{\text {(day } 7 \text { minus day } 1)}$ might be a potential predictive factor for LVRR.

Keywords: Acute myocardial infarction, ADAMTS-7, Left ventricular reverse remodeling
\end{abstract}

\section{Background}

ST-elevation myocardial infarction (STEMI) is a leading cause of heart failure and has a seriously adverse prognosis [1]. Left ventricular reverse remodeling (LVRR) is a dynamic process of myocardial repair and usually takes a few months [2]. LVRR is often accompanied with left ventricular volume decrease and left ventricular ejection fraction (LVEF) improvement [3]. It was reported that the 2-year incidence of cardiovascular endpoint events was decreased by $20 \%$ in patients with acute myocardial infarction (AMI) who achieved LVRR [3]. Therefore, LVRR is a factor of good prognosis after STEMI.

It was suggested that the degradation of the extracellular matrix (ECM) was involved in the occurrence of

${ }^{*}$ Correspondence: victorzheng@sina.com Department of Cardiology, China-Japan Friendship Hospital, Beijing 100029, China ventricular remodeling after AMI [4]. Matrix metalloproteinases (MMPs) degrade the ECM and were found to be involved in ventricular remodeling [5]. However, no specific MMP inhibitor is currently available and broadspectrum MMPs inhibitors impair the normal structure of tissues [6]. Therefore, the interest in MMPs and MMP inhibitors for the treatment of patients with AMI faded in the recent years [7].

A disintegrin and metalloproteinase with thrombospondin motifs (ADAMTS) is a family of 19 peptidases recently found to degrade ECM in a similar way than MMPs, but with a narrower substrate spectrum and higher specificity [8], making these enzymes proper targets for therapy with higher safety profile than MMPs [9]. ADAMTS-7 was reported to degrade the ECM through the degradation of cartilage oligomeric matrix proteins (COMP), which is present in the skeletal muscle system and also found to be a component of human ECM 
[10]. ADAMTS-7 is involved in vascular reconstruction through influencing the migration of smooth muscle cells and intimal neovascularization [11]. Upregulation of ADAMTS-7 could lead to calcification of vascular smooth muscle cells [12]. A previous study by our group showed that the serum levels of ADAMTS-7 were significantly increased in patients with AMI with LVEF < 35\% and were an independent predictor for heart failure after AMI [13]. However, there is no report on the relationship between serum levels of ADAMTS-7 and LVRR after STEMI.

Given the fact that serum levels of ADAMTS-7 and LVRR are associated with prognosis after STEMI, the relationship between ADAMTS-7 and LVRR is of interest. In the present study, the association between serum levels of ADAMTS-7 and LVRR after STEMI was investigated.

\section{Methods}

\section{Study design}

This was a single center prospective cohort study of 104 patients with ST-elevation myocardial infarction (STEMI) consecutively recruited between December 2012 and December 2015. All study procedures and data collections were performed at the China-Japan Friendship Hospital (Beijing, China). All patients successfully underwent reperfusion therapy within the therapeutic window (i.e., within $12 \mathrm{~h}$ after onset). The STEMI diagnosis and reperfusion therapy were in accordance with the treatment guidelines for STEMI [14]. Exclusion criteria were: (1) tumor; (2) dysfunction of liver or kidney; (3) any infection or elevated markers of inflammation at the time of blood sampling; (4) peripheral artery disease; or (5) surgery within 6 months. Thus, 63 subjects who had no history of cardiovascular diseases were recruited during routine physical examinations.

The study was approved by the ethics committee of the China-Japan Friendship Hospital. An informed consent was signed by each participant before entering the study.

\section{Interventions}

Preoperative aspirin and clopidogrel were given to all patients. The culprit vessel was defined according to clinical manifestation, echocardiography, and angiography [15]. A drug-eluting stent was implanted. The standard postoperative medication included angiotensin-converting enzyme inhibitor (ACEI), angiotensin receptor blocker (ARB), $\beta$ receptor blocker, aldosterone antagonists, statins, aspirin, and clopidogrel. All subjects received counseling about lifestyle improvements. There were no serious adverse cardiovascular events such as revascularization, fatal arrhythmias, stent thrombosis, hospitalization for any reason, or all-cause mortality within the 6-month follow-up. Stent restenosis was observed in $3 \%$ of the patients of both groups.

\section{Data collection}

Demographic (age, sex), clinical [body mass index (BMI), hypertension, diabetes, hyperlipidemia, smoking], and intervention (culprit vessel, door-to-balloon time, restenosis) variables were collected after intervention and during follow-up.

\section{Biochemistry}

Blood was sampled on days 1, 3, and 7, and in months 1 and 6 after STEMI. Baseline serum creatinine, hemoglobin, hematocrit, and high-sensitivity $\mathrm{C}$-reactive protein (hSCRP) were routinely measured before and after PCI. Baseline fasting blood glucose, blood lipids, and $\mathrm{HbA} 1 \mathrm{c}$ were tested in the morning of the first day after admission. Creatinine kinase (CK) peak, CK-MB peak, and troponin I (TNI) peak were measured every $4 \mathrm{~h}$ until the values started to decrease. Plasma B-type natriuretic peptide (BNP) levels were determined on days 1, 3, 5, and 7 after admission. All the laboratory tests were conducted at the central laboratory of cardiovascular diseases of the China-Japan Friendship Hospital.

\section{Plasma ADAMTS-7 and BNP measurement}

The blood samples $(6 \mathrm{~mL})$ were obtained from the brachial artery and stored at $4{ }^{\circ} \mathrm{C}$ in EDTA anti-coagulation tubes. The plasma was obtained after centrifugation for $15 \mathrm{~min}$ at $1000 \times \mathrm{g}$ for $30 \mathrm{~min}$. Samples were stored at $-80^{\circ} \mathrm{C}$.

ADAMTS-7 serum levels were tested by enzymelinked immunosorbent assay (ELISA) using the Human ADAMTS-7 ELISA kit (MyBioSource Inc., San Diego, CA, USA) and an ELISA reader (Spectramax M2;Molecular Devices, USA). The optical density value was obtained at $450 \mathrm{~nm}$. The detection threshold was $1.529 \mathrm{ng} / \mathrm{mL}$.

The BNP immunofluorescence assay kit was from Hengzhong Biotechnology Co., Ltd. (Shijiazhuang, China). The linear range is $5-5000 \mathrm{pg} / \mathrm{mL}$. The plate was read using a Triage Meter Plus fluorescence immunoassay analyzer (Biosite Incorporated, San Diego, CA, USA).

\section{Echocardiography}

Cardiac structure and function were assessed by twodimensional transthoracic echocardiography within $24 \mathrm{~h}$ of STEMI and after discharge for 6 months using a Vivid E9 (GE Healthcare, Waukesha, WI, USA) and two highresolution $\mathrm{M} 5 \mathrm{~S}$ probes to acquire two-dimensional apical four-chamber and two-chamber views. The endocardial boundary was manually depicted based on the definition of electrocardiographic $R$ peak as a marker of end 
diastolic stage and terminal $T$ wave as the end of the systolic stage.

The left ventricular end-diastolic volume (LVEDV), left ventricular end-systolic volume (LVESV), and left ventricular eject fraction (LVEF) were measured according to the Simpson's method [16]. LVRR was defined as the decrease of LVESV at 6 months, as $\left(\mathrm{LVESV}_{0 \text { month }}-\mathrm{LVESV}_{6 \text { months }}\right) / \mathrm{LVESV}_{0 \text { month }} \geq 15 \%$ [3].

\section{TIMI score at admission}

The TIMI score was determined at admission, as previously described $[14,17]$. The TIMI score of patients with STEMI [14], was evaluated according to the seven risk factors, one score for each risk, including: age $\geq 65$ years old; at least three risk factors of coronary heart disease; previous coronary artery stenosis $\geq 50 \%$; electrocardiographic ST segment alteration; at least two episodes of angina pectoris within $24 \mathrm{~h}$; aspirin taken 7 days before the onset of AIM; and elevated levels of myocardial markers [17].

\section{Statistical analysis}

SPSS 17.0 (IBM, Armonk, NY, USA) was used for statistical analysis. All data were tested using the ShapiroWilk normality test. If normally distributed, data were expressed as mean \pm standard deviation (SD) and compared using independent samples $t$ test. If non-normally distributed, data were expressed as median (range) and analyzed using the Mann-Whitney $U$ test. Generalized estimating equations were used to evaluate the difference in the time-dependent ADAMTS-7 changes with the $P$ value adjusted according to Bonferroni's multiple pairwise method. Categorical data were presented as frequencies and compared using the Fisher's exact test. Odds ratio (OR) and 95\% confidence interval (95\% $\mathrm{CI})$ were calculated using multivariate stepwise logistic regression analysis using LVRR at 6 months as the dependent variable. Correlation of serum ADAMTS-7 ${ }_{\text {(day }}$ 7) levels and $\triangle$ ADAMTS-7 (day 7 minus day 1) with the change in left ventricular parameters from day 1 to 6 months after STEMI was analyzed using the spearman rank correlation coefficient. The diagnostic value, sensitivity, and specificity of $\triangle$ ADAMTS- ${ }_{\text {(day } 7 \text { minus day } 1)}$ as a predictive factor were evaluated using receiver operating characteristic (ROC) curves. Two-tailed $P$-values $<0.05$ were considered statistically significant.

\section{Results}

\section{Clinical characteristics}

Fifty-six patients (54\%) with LVESV $\geq 15 \% 6$ months after STEMI were grouped as LVRR, and 48 patients (46\%) were grouped as non-LVRR. There was no difference in demographic or clinical features between the two groups (Table 1). All the patients were treated with dual anti-platelets, ACEI, $\beta$ blockers, and statins. Controls were aged $67.4 \pm 9.2$ years and $65 \%$ were men.

\section{ADAMTS-7 levels after STEMI}

Table 2 presents the time course of serum ADAMTS-7 levels after STEMI. There were no significant differences in ADAMTS-7 levels before and 1 day after surgery. The serum levels of ADAMTS-7 in patients with STEMI were significantly higher than in controls (all $P<0.05$ ). Serum ADAMTS- 7 reached its nadir 3 days after STEMI in 42 patients out of $104(40 \%)$, and the other 62 patients $(60 \%)$ showed their nadir of ADAMTS-7 levels 7 days after STEMI. Then the serum levels of ADAMTS-7 gradually increased until 6 months after STEMI $(7.24 \pm 3.94 \mathrm{ng} /$ $\mathrm{mL})$.

\section{ADAMTS-7 level comparison between STEMI patients with and without LVRR}

Serum levels of ADAMTS-7 were significantly decreased 1 week after STEMI in patients with LVRR compared with those without LVRR $(3.84 \pm 2.26$ vs. $5.02 \pm 2.54 \mathrm{ng} /$ $\mathrm{mL}, P=0.032$ ) $($ Table 3$)$. The $\triangle$ ADAMTS-7 (day 7 minus day 1$)$ in patients with LVRR was also significantly decreased $(-1.31 \pm 0.94$ vs. $-0.30 \pm 0.22 \mathrm{ng} / \mathrm{mL}, P=0.021)$ (Table 3).

\section{Correlation of serum ADAMTS-7 levels 1 week after STEMI and $\triangle A D A M T S-7_{\text {(day } 7 \text { minus day 1) }}$ with changes in LV functional parameters from day 1 to 6 months after STEMI} $\triangle$ ADAMTS- $7_{(\text {day }} 7$ minus day 1) was positively correlated with $\triangle \operatorname{LVEDV}_{(6}$ months minus day 1$)(r=0.646, P=0.029)$, $\Delta \operatorname{LVESV}_{(\text {day }} 7$ minus day 1) $(r=0.693, P=0.017)$, $\triangle \operatorname{LVEF}_{(6}$ months minus day 1) $(r=-0.523, P=0.018)$, and $\triangle \mathrm{BNP}_{(6 \text { months minus day 1) }}(r=0.701, P=0.031)$ (Table 4).

\section{Association of $\triangle$ ADAMTS-7 (day 7 minus day 1) with LVRR 6 months after STEMI}

Multivariate logistic regression analysis showed that $\triangle$ ADAMTS-7 was independently associated with LVRR in patients with STEMI (OR $=-0.322,95 \%$ $\mathrm{CI}=-0.996$ to $-0.074, P=0.028)$, while $\mathrm{CK}-\mathrm{MB}$ peak and $\triangle \mathrm{BNP}{ }_{(6 \text { months minus day } 1)}$ were not $(\mathrm{OR}=-0.095,95 \%$ $\mathrm{CI}=-0.375$ to $0.221, P=0.282$ and $\mathrm{OR}=-0.129,95 \%$ $\mathrm{CI}=-0.383$ to $0.156, P=0.137$, respectively). The ROC curve analysis for the prediction of LVRR in patients with STEMI showed that $\triangle$ ADAMTS-7 (day 7 minus day ${ }_{1 \text { ) }}$ at a cutoff value of $-0.39 \mathrm{ng} / \mathrm{mL}$ had an area under the curve of 0.896 , sensitivity of $89 \%$, and specificity of $82 \%$ (Fig. 1). 
Table 1 Characteristics of the patients with STEMI

\begin{tabular}{|c|c|c|c|}
\hline Variables & $\operatorname{LVRR}(n=56)$ & Non-LVRR $(n=48)$ & $P$ \\
\hline Age (years) & $66.6 \pm 8.7$ & $68.2 \pm 10.1$ & 0.52 \\
\hline Male, $n(\%)$ & $38(67.9)$ & $36(75.0)$ & 0.44 \\
\hline Body mass index $\left(\mathrm{kg} / \mathrm{m}^{2}\right)$ & $23.2 \pm 3.4$ & $24.6 \pm 3.2$ & 0.89 \\
\hline Hypertension history, n (\%) & $38(67.9)$ & $30(62.5)$ & 0.48 \\
\hline Diabetes history, n (\%) & $32(57.1)$ & $27(56.2)$ & 0.31 \\
\hline History of hyperlipidemia, n (\%) & $29(51.8)$ & $27(56.2)$ & 0.26 \\
\hline Smoking history, $n(\%)$ & $18(32.1)$ & $18(37.5)$ & 0.37 \\
\hline Culprit vessel, anterior descending branch, $n(\%)$ & $29(51.8)$ & $24(50.0)$ & 0.53 \\
\hline Single vessel, $n(\%)$ & $38(67.9)$ & $33(68.8)$ & 0.61 \\
\hline Door-to-balloon time (min) & $85.5 \pm 38.4$ & $84.3 \pm 38.0$ & 0.91 \\
\hline Restenosis, $n(\%)$ & $3(5.4)$ & $3(6.3)$ & 0.66 \\
\hline CK peak (IU/L) & $2537 \pm 1268$ & $2664 \pm 1067$ & 0.73 \\
\hline CK-MB peak (IU/L) & $202 \pm 165$ & $269 \pm 174$ & 0.33 \\
\hline TNI peak (ng/mL) & $22.47 \pm 6.01$ & $24.36 \pm 4.20$ & 0.62 \\
\hline Serum creatinine (mol/L) & $87.2 \pm 18.57$ & $93.2 \pm 34.16$ & 0.27 \\
\hline Hemoglobin $(\mathrm{g} / \mathrm{dL})$ & $13.7 \pm 1.5$ & $13.6 \pm 1.4$ & 0.19 \\
\hline Hematocrit (\%) & $57.2 \pm 14.3$ & $46.8 \pm 5.6$ & 0.29 \\
\hline Fasting blood glucose (mmol/L) & $8.42 \pm 4.63$ & $8.44 \pm 4.96$ & 0.50 \\
\hline Glycosylated hemoglobin (\%) & $6.47 \pm 1.73$ & $6.36 \pm 1.25$ & 0.66 \\
\hline Serum cholesterol (mmol/L) & $4.88 \pm 1.79$ & $4.92 \pm 1.21$ & 0.58 \\
\hline High density lipoprotein cholesterol (mmol/L) & $1.04 \pm 0.22$ & $1.07 \pm 0.32$ & 0.54 \\
\hline Low density lipoprotein cholesterol (mmol/L) & $3.62 \pm 1.22$ & $3.57 \pm 1.24$ & 0.74 \\
\hline $\mathrm{hsCRP}(\mathrm{mg} / \mathrm{L})$ & $0.56 \pm 0.39$ & $0.57 \pm 0.34$ & 0.87 \\
\hline TIMI score & $2.84 \pm 1.22$ & $2.69 \pm 1.16$ & 0.51 \\
\hline LVEDV (mL) & $190.1 \pm 29.6$ & $181.4 \pm 38.3$ & 0.71 \\
\hline LVESV (mL) & $92.8 \pm 26.5$ & $85.2 \pm 33.1$ & 0.34 \\
\hline LVEF (\%) & $52.3 \pm 8.5$ & $53.5 \pm 12.1$ & 0.52 \\
\hline Plasma BNP peak levels (pg/mL) & $168.4 \pm 129.8$ & $223.7 \pm 213.5$ & 0.35 \\
\hline
\end{tabular}

CK creatinine kinase, CK-MB MB fraction of creatinine kinase, TNI troponin I, hSCRP high sensitivity C-reactive protein, TIMI thrombolysis in myocardial infarction, LVEDV left ventricular end-diastolic volume, LVESV left ventricular end-systolic volume, LVEF left ventricular ejection fraction, BNP B-type natriuretic peptide

Table 2 Time course of serum ADAMTS-7 levels in patients with STEMI

\begin{tabular}{llllllll}
\hline & \multicolumn{2}{l}{ STEMI $(\boldsymbol{n}=\mathbf{1 0 4})$} & & & \multicolumn{2}{c}{ Controls $(\boldsymbol{n}=\mathbf{6 3})$} \\
\cline { 2 - 6 } & Day 0 & Day 1 & Day 3 & Day 7 & 1 month & 6 months \\
\hline Serum ADAMTS- 7 (ng/mL) & $5.03 \pm 2.99$ & $5.14 \pm 3.06$ & $4.43 \pm 2.19$ & $4.32 \pm 2.42$ & $5.02 \pm 2.83$ & $7.24 \pm 3.94$ & $1.62 \pm 1.43$ \\
$P$ (vs. day 1) & 0.083 & - & 0.024 & 0.026 & 0.31 & 0.042 & 0.001 \\
$P$ (vs. controls) & 0.006 & 0.006 & 0.012 & 0.009 & 0.008 & 0.002 & - \\
\hline
\end{tabular}

Table 3 Comparison of serum levels of ADAMTS-7 and $\triangle A D A M T S-7$ between patients with and without LVRR

\begin{tabular}{|c|c|c|c|c|c|c|c|c|c|}
\hline \multirow[t]{2}{*}{ Group } & \multicolumn{5}{|c|}{ Serum ADAMTS-7 levels (ng/mL) } & \multicolumn{4}{|c|}{$\triangle$ ADAMTS-7 (ng/mL) } \\
\hline & Day 1 & Day 3 & Day 7 & 1 month & 6 months & Day 3 & Day 7 & 1 month & 6 months \\
\hline $\operatorname{LVRR}(n=56)$ & $5.33 \pm 3.22$ & $4.27 \pm 2.32$ & $3.84 \pm 2.26$ & $5.01 \pm 2.94$ & $7.09 \pm 3.89$ & $-1.04 \pm 0.27$ & $-1.31 \pm 0.94$ & $-0.29 \pm 0.84$ & $1.79 \pm 1.64$ \\
\hline Non-LVRR $(n=48)$ & $5.18 \pm 3.10$ & $4.89 \pm 2.21$ & $5.02 \pm 2.54$ & $5.04 \pm 2.68$ & $7.36 \pm 3.96$ & $-0.59 \pm 0.21$ & $-0.30 \pm 0.22$ & $0.04 \pm 0.61$ & $2.22 \pm 1.96$ \\
\hline$P$ & 0.079 & 0.085 & 0.032 & 0.242 & 0.241 & 0.053 & 0.021 & 0.143 & 0.086 \\
\hline
\end{tabular}

LVRR left ventricular reverse remodeling

${ }^{a}$ Calculated as the tested time point minus day 1 
Table 4 Correlation of serum ADAMTS-7 (day 7) levels

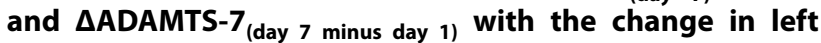
ventricular parameters and BNP from day 1 to 6 months after STEMI

\begin{tabular}{|c|c|c|c|c|}
\hline \multirow[t]{2}{*}{ Variable } & \multicolumn{2}{|c|}{$\begin{array}{l}\text { Serum ADAMTS-7 } \\
\text { (day 7) }(\mathrm{ng} / \mathrm{mL})\end{array}$} & \multicolumn{2}{|c|}{$\begin{array}{l}\triangle A D A M T S-7 \\
\text { (day } 7 \text { minus day 1) }(\mathrm{ng} / \mathrm{mL})\end{array}$} \\
\hline & $r$ & $P$ & $r$ & $P$ \\
\hline$\triangle \operatorname{LVEDV}(\mathrm{mL})$ & 0.573 & 0.043 & 0.646 & 0.029 \\
\hline$\triangle \mathrm{LVESV}(\mathrm{mL})$ & 0.467 & 0.075 & 0.693 & 0.017 \\
\hline$\triangle \operatorname{LVEF}(\%)$ & -0.265 & 0.262 & -0.523 & 0.018 \\
\hline$\triangle B N P(p g / m L)$ & 0.648 & 0.039 & 0.701 & 0.031 \\
\hline
\end{tabular}

LVEDV left ventricular end-diastolic volume, LVESV left ventricular end-systolic volume, LVEF left ventricular ejection fraction, BNP B-type natriuretic peptide

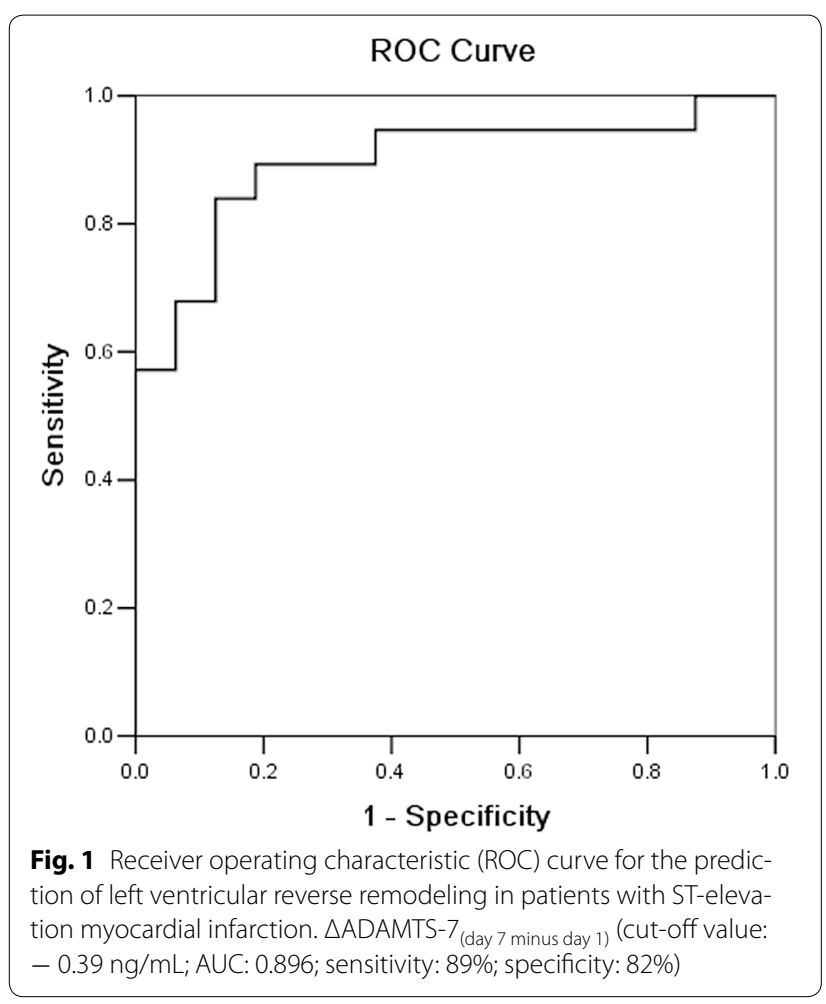

\section{Discussion}

LVRR in patients with STEMI is closely associated with prognosis [3]. Compared with MMPs, ADAMTS-7 has a narrower substrate spectrum and might be a better pharmacological target [10]. In addition, serum levels of ADAMTS-7 might be used for the prognosis of AMI [13], but the contribution of ADAMTS-7 to LVRR has not been reported. Therefore, the present study aimed to investigate the relationship between serum ADAMTS-7 level and LVRR after STEMI. Results showed that serum ADAMTS-7 levels in patients with STEMI were significantly higher than in controls. They gradually decreased from day 3 to day 7 and then gradually increased at 6 months after STEMI. Serum ADAMTS-7 levels 1 week after STEMI and $\triangle$ ADAMTS-7 ${ }_{(\text {day } 7 \text { minus day } 1)}$ were significantly decreased in patients with LVRR compared with those without LVRR. $\triangle$ ADAMTS-7 ${ }_{\text {(day } 7 \text { minus day } 1)}$ was positively correlated with $\triangle \operatorname{LVEDV}_{(6}$ months minus day 1$)$ and $\triangle \operatorname{LVESV}_{(6}$ months minus day 1), and negatively correlated with $\triangle \operatorname{LVEF}_{(6 \text { months minus day } 1)}$. $\triangle$ ADAMTS-7 $_{\text {(day } 7 \text { minus day } 1)}$ was an independent risk factor for LVRR after STEMI.

The ADAMTS family belongs to the inflammatory factors and plays critical roles in many diseases [18]. In this study, ADAMTS-7 levels were significantly increased at the early stage of AMI, probably because of plaque rupture and inflammatory factors being released [19]; ADAMTS-7 levels gradually decreased from day 3 to day 7 and gradually increased afterwards. ADAMTS-7 is considered to participate in the degradation of ECM mediated by COMP, which facilitates LVRR [13]. There were no significant differences of serum ADAMTS-7 between patients with and without LVRR on the first day after STEMI, but ADAMTS-7 levels were significantly decreased in patients with LVRR 1 week later, suggesting that ADAMTS-7 decrease is involved in LVRR, which is supported by a previous study [13] and by results in other MMPs [20]. The analysis showed that $\triangle$ ADAMTS-7 was not influenced by the clinical characteristics, as previously shown [13], and that LVRR was the only factor affected by the serum levels of ADAMTS-7. Therefore, it might be speculated that $\triangle$ ADAMTS-7 ${ }_{\text {(day } 7 \text { minus day } 1)}$ might reflect LVRR as an early diagnostic factor. Indeed, this present study suggests that patients with $\triangle$ ADAMTS- $7 \geq-0.39$ might be used to guide the management of these patients. Nevertheless, because the involvement of ADAMTS-7 in LVRR has only been recently described, additional studies are necessary to determine its exact role and contribution in LVRR. In addition, since other MMPs are also associated with LVRR, more comprehensive studies should examine these factors together. Indeed, a recent study showed that

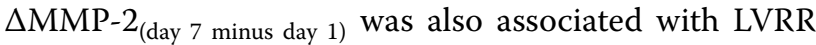
and that a $\triangle M M P-2_{(\text {day } 7 \text { minus day 1) }}$ of $<-158.5 \mathrm{ng} / \mathrm{mL}$ predicted LVRR with $91.7 \%$ sensitivity and $76.9 \%$ specificity [20]. Combining different MMPs could yield an even better accuracy.

The exact mechanisms of ADAMTS-7 for cardiac remodeling are poorly known. ADAMTS-7 is widely expressed in the heart and large vessels, but knockout of ADAMTS-7 under physiological conditions has no significant effect on the cardiac structure and function of mice [21]. There is little expression of ADAMTS-7 in the myocardium rats 28 days after myocardial infarction [22]. Cultured synovial fibroblasts from healthy individuals 
and patients with osteoarthritis can secrete ADAMTS-7 [23]. Cartilage oligomeric matrix proteins (COMP) can induce the expression of type I collagen in hepatic stellate cells [24]. C-end spherical areas of COMP can be connected to types I, II, and IX collagen, suggesting that they may be involved in maintaining the integrity of the collagen network. Another important function of COMP is to assist the secretion of type I collagen [25]. Collagen content is low in the ECM after AMI [25] and the ventricular cavity is enlarged and the ventricular wall is thinned [26]. Therefore, it was suspected that the decrease in COMP levels after myocardial infarction promoted ventricular dilatation. The degradation of COMP in cardiac fibroblasts could result in a decrease in type I collagen secretion that changes ECM components and promotes ventricular dilatation [25]. ADAMTS-7 includes four TSP motifs domains at C-end, which are binding sites for COMP [27]. ADAMTS-7 cannot degrade COMP in ECM in various tissues $[12,28]$, but can degrade COMP in synovial fibroblasts [23]. Thus, ADAMTS-7 may change ECM components and promote ventricular dilatation by promoting COMP degradation in cardiac fibroblasts. Nevertheless, the exact mechanisms still require confirmation, but the present showed that the ADAMTS-7 levels correlated with BNP levels, a well-known marker of myocardial damage. This association is supported by previous studies [13, 29, 30].

This study is not without limitations. Firstly, the sample size was small and from a single center, and the followup period was relatively short. Patients with symptoms of STEMI but normal angiography could be included in the future as supplementary controls. Secondly, ADAMTS-7 was only tested in the peripheral blood and not in the myocardial tissues. Thirdly, the mechanisms of $\triangle$ ADAMTS- $7_{\text {(day } 7 \text { minus day 1) }}$ remain to be elucidated, as well as the effect of circulating inflammatory factors on ADAMTS-7 expression. Fourthly, it is also unknown whether some drugs such as ACEI or ARBs influence the levels of ADAMTS-7, but this factor is unlikely to have affected the results of the present study since all patients were treated with the same drugs and according to the same guidelines. Fifthly, because rheumatism is not routinely examined at our department, patients with rheumatisms were not excluded even if rheumatism could have affected the results [28], but patients with any infection at the time of blood sampling were excluded, and the prevalence of rheumatism in the Chinese population is not high [31]. Nevertheless, the cut-off value of $\triangle$ ADAMTS-7 (day 7 minus day 1) was $-0.39 \mathrm{ng} / \mathrm{mL}$, for a positive rate in the LVRR group of $94.6 \%$. In addition, echocardiography revealed no overt case of rheumatic heart disease. Studies with a larger sample size and the corresponding fundamental studies on the mechanisms of $\triangle$ ADAMTS-7 ${ }_{\text {(day } 7 \text { minus day } 1)}$ are needed to confirm our findings.

\section{Conclusions}

In conclusion, $\triangle$ ADAMTS-7 (day 7 minus day 1) was independently associated with LVRR after STEMI, and might be a potential predictive factor for LVRR.

\begin{abstract}
Abbreviations
LVRR: left ventricular reverse remodeling; AMI: acute myocardial infarction; LVESV: left ventricular end-systolic volume; ECM: extracellular matrix; ADAMTS: a disintegrin and metalloproteinase with thrombospondin motifs; COMP: cartilage oligomeric matrix proteins; ACEl: angiotensin-converting enzyme inhibitor; ARB: angiotensin receptor blocker; BMI: body mass index; ELISA: enzyme-linked immunosorbent assay; BNP: B-type natriuretic peptide; LVEDV: left ventricular end-diastolic volume; LVEF: left ventricular eject fraction; NSTEMI: non-ST-elevation myocardial infarction; UAP: unstable angina; SD: standard deviation; STEMI: ST-elevation myocardial infarction; ROC: receiver operating characteristic.
\end{abstract}

\section{Authors' contributions}

WW, LL and JZ carried out the studies, participated in collecting data, and drafted the manuscript. CY and YG performed the statistical analysis and participated in its design and ELISA. SF and XY completed UCG. YW helped to draft the manuscript. All authors read and approved the final manuscript.

\section{Acknowledgements}

The authors acknowledge the invaluable participation of the subjects, as well as the help from the laboratory staff.

\section{Competing interests}

The authors declare that they have no competing interests.

\section{Availability of data and materials}

Not applicable.

\section{Consent for publication}

An informed consent was signed by each participant before entering the study.

\section{Ethics approval and consent to participate}

The study was approved by the ethics committee of the China-Japan Friendship Hospital.

\section{Funding}

This work was supported by Grants from the National Natural Science Fund (30770865; 81170287), Beijing Lisheng Cardiovascular Health Foundation (BYX2013-019), the China-Japan Friendship Hospital Youth Science and Technology Excellence Project (2014-QNYC-B-13), and the China-Japan Friendship Hospital research topic within the hospital (2014-4-MS-23).

\section{Publisher's Note}

Springer Nature remains neutral with regard to jurisdictional claims in published maps and institutional affiliations.

Received: 25 August 2016 Accepted: 3 February 2018

Published online: 10 March 2018

\section{References}

1. Cohn JN, Ferrari R, Sharpe N. Cardiac remodeling-concepts and clinical implications: a consensus paper from an international forum on cardiac remodeling. Behalf of an International Forum on Cardiac Remodeling. J Am Coll Cardiol. 2000;35:569-82. 
2. Kelly D, Khan SQ, Thompson M, Cockerill G, Ng LL, Samani N, et al. Plasma tissue inhibitor of metalloproteinase-1 and matrix metalloproteinase-9: novel indicators of left ventricular remodelling and prognosis after acute myocardial infarction. Eur Heart J. 2008;29:2116-24.

3. Funaro S, La Torre G, Madonna M, Galiuto L, Scara A, Labbadia A, et al. Incidence, determinants, and prognostic value of reverse left ventricular remodelling after primary percutaneous coronary intervention: results of the acute myocardial infarction contrast imaging (AMICI) multicenter study. Eur Heart J. 2009;30:566-75.

4. Ahmed SH, Clark LL, Pennington WR, Webb CS, Bonnema DD, Leonardi $\mathrm{AH}$, et al. Matrix metalloproteinases/tissue inhibitors of metalloproteinases: relationship between changes in proteolytic determinants of matrix composition and structural, functional, and clinical manifestations of hypertensive heart disease. Circulation. 2006;113:2089-96.

5. Spinale FG. Myocardial matrix remodeling and the matrix metalloproteinases: influence on cardiac form and function. Physiol Rev. 2007:87:1285-342.

6. Overall $\mathrm{CM}$, Kleifeld $\mathrm{O}$. Towards third generation matrix metalloproteinase inhibitors for cancer therapy. Br J Cancer. 2006;94:941-6.

7. Hu J, Van den Steen PE, Sang QX, Opdenakker G. Matrix metalloproteinase inhibitors as therapy for inflammatory and vascular diseases. Nat Rev Drug Discov. 2007:6:480-98.

8. Apte SS. A disintegrin-like and metalloproteinase (reprolysin type) with thrombospondin type 1 motifs: the ADAMTS family. Int J Biochem Cell Biol. 2004;36:981-5.

9. Pasternak B, Aspenberg P. Metalloproteinases and their inhibitorsdiagnostic and therapeutic opportunities in orthopedics. Acta Orthop. 2009;80:693-703.

10. Riessen R, Fenchel M, Chen H, Axel DI, Karsch KR, Lawler J. Cartilage oligomeric matrix protein (thrombospondin-5) is expressed by human vascular smooth muscle cells. Arterioscler Thromb Vasc Biol. 2001;21:47-54.

11. Wang $L$, Wang $X$, Kong W. ADAMTS-7, a novel proteolytic culprit in vascular remodeling. Sheng Li Xue Bao. 2010;62:285-94.

12. Du Y, Gao C, Liu Z, Wang L, Liu B, He F, et al. Upregulation of a disintegrin and metalloproteinase with thrombospondin motifs- 7 by miR-29 repression mediates vascular smooth muscle calcification. Arterioscler Thromb Vasc Biol. 2012;32:2580-8.

13. Wu W, Zhou Y, Li Y, Li J, Ke Y, Wang Y, et al. Association between plasma ADAMTS-7 levels and ventricular remodeling in patients with acute myocardial infarction. Eur J Med Res. 2015:20:27.

14. O'Gara PT, Kushner FG, Ascheim DD, Casey DE Jr, Chung MK, de Lemos JA, et al. 2013 ACCF/AHA guideline for the management of ST-elevation myocardial infarction: a report of the American College of Cardiology Foundation/American Heart Association Task Force on Practice Guidelines. Circulation. 2013;127:e362-425.

15. Fleg JL, Stone GW, Fayad ZA, Granada JF, Hatsukami TS, Kolodgie FD, et al. Detection of high-risk atherosclerotic plaque: report of the NHLBI Working Group on current status and future directions. JACC CardiovasC Imaging. 2012;5:941-55.
16. Sahn DJ, DeMaria A, Kisslo J, Weyman A. Recommendations regarding quantitation in M-mode echocardiography: results of a survey of echocardiographic measurements. Circulation. 1978;58:1072-83.

17. Lempereur M, Moonen M, Gach O, Lancellotti P. European society for C. [2011 ESC guidelines for the management of acute coronary syndromes without ST segment elevation]. Rev Med Liege. 2012;67:8-10.

18. Gao YX, Yu CA, Lu JH, Gao HM, Li G, Kong W, et al. ADAMTS-7 expression increases in the early stage of angiotensin II-induced renal injury in elderly mice. Kidney Blood Press Res. 2013;38:121-31.

19. Salter RC, Ashlin TG, Kwan AP, Ramji DP. ADAMTS proteases: key roles in atherosclerosis? J Mol Med (Berl). 2010:88:1203-11.

20. Morishita T, Uzui H, Mitsuke Y, Arakawa K, Amaya N, Kaseno K, et al. Predictive utility of the changes in matrix metalloproteinase- 2 in the early phase for left ventricular reverse remodeling after an acute myocardial infarction. J Am Heart Assoc. 2015;4:e001359.

21. Bauer RC, Tohyama J, Cui J, Cheng L, Yang J, Zhang X, et al. Knockout of Adamts7, a novel coronary artery disease locus in humans, reduces atherosclerosis in mice. Circulation. 2015;131:1202-13.

22. Wu L, Mei L, Chong L, Huang Y, Li Y, Chu M, et al. Olmesartan ameliorates pressure overload-induced cardiac remodeling through inhibition of TAK1/p38 signaling in mice. Life Sci. 2016;145:121-6.

23. Perez-Garcia S, Carrion M, Gutierrez-Canas I, Gonzalez-Alvaro I, Gomariz $\mathrm{RP}$, Juarranz Y. VIP and CRF reduce ADAMTS expression and function in osteoarthritis synovial fibroblasts. J Cell Mol Med. 2016;20:678-87.

24. Magdaleno F, Arriazu E, Ruiz de Galarreta M, Chen Y, Ge X, Conde de la Rosa L, et al. Cartilage oligomeric matrix protein participates in the pathogenesis of liver fibrosis. J Hepatol. 2016;65:963-71.

25. Schulz JN, Nuchel J, Niehoff A, Bloch W, Schonborn K, Hayashi S, et al. COMP-assisted collagen secretion-a novel intracellular function required for fibrosis. J Cell Sci. 2016;129:706-16.

26. Huang Y, Xia J, Zheng J, Geng B, Liu P, Yu F, et al. Deficiency of cartilage oligomeric matrix protein causes dilated cardiomyopathy. Basic Res Cardiol. 2013:108:374.

27. Liu CJ, Kong W, Ilalov K, Yu S, Xu K, Prazak L, et al. ADAMTS-7: a metalloproteinase that directly binds to and degrades cartilage oligomeric matrix protein. FASEB J. 2006;20:988-90.

28. Zhang Y, Wei F, Liu CJ. Overexpression of ADAMTS-7 leads to accelerated initiation and progression of collagen-induced arthritis in mice. Mol Cell Biochem. 2015;404:171-9.

29. Wu W, Wang H, Yu C, Li J, Gao Y, Ke Y, et al. Association of ADAMTS-7 levels with cardiac function in a rat model of acute myocardial infarction. Cell Physiol Biochem. 2016:38:950-8.

30. Yu J, Zhou B, Yu H, Han J, Cui M, Zhang F, et al. Association between plasma ADAMTS-7 levels and severity of disease in patients with stable obstructive coronary artery disease. Medicine (Baltimore). 2016;95:e5523.

31. Felson DT. Comparing the prevalence of rheumatic diseases in China with the rest of the world. Arthritis Res Ther. 2008;10:106.

\section{Submit your next manuscript to BioMed Central and we will help you at every step:}

- We accept pre-submission inquiries

- Our selector tool helps you to find the most relevant journal

- We provide round the clock customer support

- Convenient online submission

- Thorough peer review

- Inclusion in PubMed and all major indexing services

- Maximum visibility for your research

Submit your manuscript at www.biomedcentral com/submit
Ciomed Central 